\title{
Ética, direitos dos usuários e políticas de humanização da atenção à saúde
}

Ethics, users' rights and policies of humanization of healthcare

Paulo Antonio de Carvalho Fortes

Médico sanitarista. Professor Associado do Departamento de

Prática de Saúde Pública da Faculdade de Saúde Pública - USP

E-mail: pacfuspœusp.br

\begin{abstract}
Resumo
O artigo trata da evolução das políticas públicas de humanização dos serviços de saúde no Brasil. No campo da atenção em saúde, o termo humanização tem sido utilizado com diferentes significados e entendimentos, relacionando-o com os direitos dos pacientes e a ética voltada ao respeito ao outro. A partir dos anos 90, a humanização da atenção à saúde vem sendo tratada como política pública, iniciando-se no ambiente hospitalar, e, atualmente, sendo dirigida para todos os níveis de atenção de saúde.
\end{abstract}

Palavras-chave: Ética; Direitos dos usuários; Humanização em saúde

\begin{abstract}
The article shows the evolution of public policies of humanization of healthcare in Brazil. Humanization was first related to patients' rights and ethics regarding respect for the others. In the nineties humanization is vieved as a public policies. Nowadays it is oriented to all services of health care.
\end{abstract}

Key words: Organizational Ethics; Patients' Rights; Humanization in Health 


\section{Ética e Humanização}

Se a organização e o funcionamento dos sistemas de saúde na década de 1980 foram marcados pelos princípios da eficácia, otimização e eficiência, a partir dos anos 1990 são incorporadas as noções de qualidade, eqüidade, satisfação e autonomia do usuário. Neste bojo se situa a humanização da atenção à saúde.

Segundo Ribeiro (2002), o humanismo está relacionado a uma ética baseada na condição humana e nos ideais partilhados pelos homens, assim como a um conjunto de valores que fundamentam a compreensão dos empreendimentos científicos e tecnológicos. Pode ser expresso pelo caráter e qualidade da atenção, levando em conta interesses, desejos e necessidades dos atores sociais implicados nesta área.

Consideramos difícil se falar em humanização sem relaciona-la à ética, sendo esta última um dos instrumentos de que o homem lança mão para garantir a coesão social. Ética é a reflexão crítica sobre o comportamento humano que interpreta, discute e problematiza os valores, os princípios e as regras morais, à procura da "boa vida" em sociedade, do bom convívio social (Fortes, 1998).

Humanizar na atenção à saúde é entender cada pessoa em sua singularidade, tendo necessidades específicas, e, assim, criando condições para que tenha maiores possibilidades para exercer sua vontade de forma autônoma. Segundo Rech (2003), é tratar as pessoas levando em conta seus valores e vivências como únicos, evitando quaisquer formas de discriminação negativa, de perda da autonomia, enfim, é preservar a dignidade do ser humano.

A reflexão humanística não enfoca somente problemas e necessidades biológicas, mas abrange as circunstâncias sociais, éticas, educacionais e psíquicas presentes nos relacionamentos humanos existentes nas ações relativas à atenção em saúde. Como refere Zoboli (2003), o estado de saúde e o processo saúdedoença em cada pessoa são vivenciados como condição única, enquanto que para os profissionais de saúde as situações individuais são vividas como casos, de um pretenso ponto de vista objetivo, dentro de parâmetros supostamente racionais e científicos.

Humanizar refere-se à possibilidade de uma transformação cultural da gestão e das práticas desenvolvidas nas instituições de saúde, assumindo uma pos- tura ética de respeito ao outro, de acolhimento do desconhecido, de respeito ao usuário entendido como um cidadão e não apenas como um consumidor de serviços de saúde.

\section{A Humanização e os Direitos dos Usuá- rios da Saúde}

No campo da atenção em saúde o termo humanização tem sido utilizado com diferentes significados e entendimentos. 0 conceito vem se modificando no decorrer dos últimos anos, confundindo-se historicamente, nas fases iniciais, com a luta por direitos dos pacientes/usuários. Podemos dizer que humanização da atenção à saúde tem seu fundamento na Declaração Universal dos Direitos Humanos, que em seu art. $1^{\circ}$ afirma: "Todos os seres humanos nascem livres e iguais em dignidade e em direitos. Dotados de razão e de consciência, devem agir uns para com os outros em espírito de fraternidade".

A reflexão sobre práticas humanizadoras em saúde se inicia nos anos 1970 por meio da discussão e luta sobre os "direitos do paciente". A primeira declaração de direitos dos pacientes a ser reconhecida pela literatura foi emitida pelo Hospital Mont Sinai, em Boston/ USA, em 1972. Um ano depois, a Associação Americana de Hospitais lança a Patient's Bill of Rights [Carta dos Direitos dos Pacientes], que foi posteriormente revisada em 1992 (Fortes, 1998).

De grande importância para a fundamentação sobre a humanização na saúde foi a Declaração da Conferência Internacional sobre Cuidados Primários de Saúde, co-patrocinada e organizada pela Organização Mundial de Saúde e pela UNICEF, que aconteceu em Alma-Ata, capital do Kazaquistão Soviético, de 6 a 12 de setembro de 1978, a qual reafirmou que a saúde é um estado de bem-estar completo, físico, mental e social, e não somente a ausência de doenças ou enfermidades, devendo ser compreendida como um direito humano fundamental. A Declaração enfatizou que a obtenção do mais alto nível de saúde possível é o objetivo social mais importante a ser atingido pelos sistemas de saúde, sendo que as pessoas devem ter o direito e a obrigação de participar, individual e coletivamente, no planejamento e na implementação de seus cuidados com saúde. 
No continente europeu foram emitidos diversos documentos por organismos transnacionais desde o final dos anos 1970. Em 1979, a Comunidade Econômica Européia se manifestou mediante a "Carta do Doente Usuário de Hospital”. A Carta afirmou o direito do paciente hospitalizado à autodeterminação, o direito para aceitar ou recusar os cuidados propostos pelos profissionais de saúde tanto para diagnóstico como para tratamento, como também a obrigatoriedade do fornecimento das informações sobre todos os fatos referentes ao estado de saúde.

Em 1984, ampliando o enfoque hospitalar dos outros documentos, o Parlamento Europeu adota a Carta Européia dos Direitos do Paciente, na qual se encontram expressos, entre outros aspectos, o direito à informação sobre o tratamento e o prognóstico, o direito à consulta, pelo usuário, a seu prontuário médico, assim como o direito de consentir ou de recusar ser submetido a tratamentos.

No Brasil, além das bases constitucionais relativas a direitos individuais, coletivos e sociais, a legislação infraconstitucional referente ao setor de saúde traz diretrizes e normas que se referem, de forma direta ou indireta, à humanização da atenção em saúde, tais como a preservação da autonomia das pessoas na defesa de sua integridade física e moral, à igualdade da assistência à saúde, sem preconceitos ou privilégios de qualquer espécie, e o direito à informação das pessoas assistidas sobre sua saúde (Lei federal 8o80/9o, art. $7^{\circ}$, III, IV e V).

Outras normas legais também dispuseram sobre tópicos relacionados à humanização da atenção à saúde. Por exemplo, em conformidade aos arts. 11 e 12 do Estatuto da Criança e do Adolescente, os estabelecimentos de saúde devem proporcionar condições para a permanência em tempo integral de um dos pais ou responsável, nos casos de internação de criança ou adolescente, além de manter alojamento conjunto possibilitando ao neonato estar junto à sua mãe.

É também interessante se destacar que no Estado de São Paulo, em 1995, a questão dos direitos do paciente foi contemplada no Código de Saúde do Estado de São Paulo, lei complementar 791/95. Como exemplo, encontramos em seu art. $3^{\circ}$, IV, disposições legais referentes aos indivíduos poderem decidir livremente, sobre a aceitação ou a recusa da prestação da assistência á saúde, ao direito a ser tratado com preste- za, privacidade e respeito, assim como o de ser informado sobre seu estado de saúde e as alternativas possíveis de tratamento.

Ainda em 1995, foi emitido importante documento - a Cartilha dos Direitos do Paciente - pelo Conselho de Saúde do Estado de São Paulo, a partir de estudos efetuados pelo Fórum Permanente de Patologias Crônicas, cujas diretrizes e os princípios aí dispostos foram inspiradores da lei estadual $\mathrm{n}^{0} 10241$, promulgada em março de 1999, relativa aos direitos dos usuários dos serviços e das ações de saúde no Estado.

As normas deste ato legal expressam, entre outros, o direito dos usuários a ter um atendimento digno, atencioso e respeitoso; a ser identificado e tratado pelo seu nome ou sobrenome; a não ser identificado ou tratado por números, códigos ou de modo genérico, desrespeitoso, ou preconceituoso; a ter resguardado o segredo sobre seus dados pessoais, através da manutenção do sigilo profissional, desde que não acarrete riscos a terceiros ou à saúde pública; a poder identificar as pessoas responsáveis, direta e indiretamente, por sua assistência; receber informações claras, objetivas e compreensíveis sobre hipóteses diagnósticas, diagnósticos realizados, exames solicitados e ações terapêuticas; a consentir ou recusar, de forma livre, voluntária e esclarecida, com adequada informação, procedimentos diagnósticos ou terapêuticos a serem nele realizados; a acessar, a qualquer momento, o seu prontuário médico (Art. $2^{\circ}$, itens I a VIII).

Essas iniciativas tiveram repercussões em outros estados brasileiros, sendo que, recentemente, no município de Belo Horizonte/MG, foi promulgada a lei no 8926, de o2 de agosto de 2004, que "dispõe sobre os direitos do usuário dos serviços e das ações de saúde no município", a qual é voltada fundamentalmente para a humanização dos serviços de saúde.

\section{A Humanização da Atenção à Saúde como Política Pública}

O final da década de 90 foi marcado pela ampliação de proposições políticas governamentais referentes à humanização na atenção à saúde. Em 2001, o Ministério da Saúde lança o Programa Nacional de Humanização da Assistência Hospitalar (PNHAH). Programa este que propõe um conjunto de ações integradas 
com o objetivo de alterar os padrões de assistência aos usuários no ambiente hospitalar público. O Programa enfocava a necessidade de ocorrer uma transformação cultural no ambiente hospitalar, orientada pelo atendimento humanizado ao usuário, entendendo que resultaria em maior qualidade e eficácia das ações desenvolvidas. Expressava que as relações humanas que caracterizam o atendimento à saúde exigem “agregar à eficiência técnica e científica uma ética que considere e respeite a singularidade das necessidades do usuário e do profissional, que acolha o desconhecido e imprevisível, que aceite os limites de cada situação".

Um forte diferencial sentido em relação às propostas de "direitos dos usuários" é que o Programa incorporou a preocupação com a valorização, a capacitação e o desenvolvimento dos trabalhadores do setor saúde, dos encarregados da tarefa do cuidar. As políticas de saúde devem proporcionar as condições necessárias para o exercício das tarefas cotidianas e devem criar condições para que os que cuidam possam também ter suas necessidades satisfeitas.

O Programa objetivou capacitar os trabalhadores da saúde para lidarem com a dimensão psicossocial dos usuários e de suas famílias. Estimulou o trabalho em equipe multiprofissional, entendendo ser esta uma das condições essenciais para a eficácia da prática humanizada, devido à exacerbada especialização e tecnificação dos atos realizados por profissionais de saúde e ao aparecimento de novas formas organizacionais do trabalho que resultam em progressivo afastamento dos profissionais de saúde dos usuários sob sua responsabilidade, diminuindo o vínculo nas relações, tornando-as mais distantes, impessoais e despersonalizadas.

Essa assertiva é condizente com o estudo realizado por Rech (2003) com gerentes de serviços de uma unidade hospitalar de grande porte na região metropolitana de São Paulo, que indicou que a práticas humanizadoras devem se ater a todos os atores sociais relacionados na atenção à saúde, e não somente a uma ou duas categorias profissionais, notadamente médicos e enfermeiros.

O PNHAH propôs a valorização da formação educacional dos profissionais de saúde a fim de possibilitar a incorporação de valores e atitudes de respeito à vida humana, consoante à compreensão de que a qualidade em saúde deve ser composta de competência técnica e de interação, não se resumindo somente a aspectos técnicos ou organizacionais. 0 documento-base do Programa salienta ainda que é imprescindível a melhoria da imagem do serviço público de saúde, não só junto aos usuários, mas também junto aos próprios profissionais de saúde, pois "o profissional que se sente respeitado pela instituição à qual pertence está mais apto a atender com eficiência” e de forma mais humana.

O Programa destacou ainda o papel do gestor para dar eficácia ao processo de humanização dos serviços de saúde, pois este é um dos principais responsáveis por proporcionar condições adequadas para que os funcionários e servidores sejam valorizados em seu trabalho e os usuários tenham seus direitos garantidos.

Em 2003, a nova gestão do Ministério da Saúde inicia a condução de uma proposta que expandisse a humanização para além do ambiente hospitalar e estabeleceu a Política Nacional de Humanização da Atenção e Gestão em Saúde no SUS - HumanizaSUS. Esta política pretende ter um caráter transversal, visando atingir a todos níveis de atenção à saúde, entendendo humanização como uma transformação cultural da atenção aos usuários e da gestão de processos de trabalho que deve perpassar todas ações e serviços de saúde.

A proposta do HumanizaSUS apresenta algumas diferenciações com as anteriores ao incorporar no conceito de humanização empregado, além dos direitos dos usuários e do "cuidar do cuidador", a necessidade da melhoria de aspectos organizacionais do sistema e dos serviços de saúde, aspectos que se tornam fundamentais para proporcionar adequadas condições para o desenvolvimento de medidas humanizadoras. Com isto, resgatam-se princípios e diretrizes da construção do SUS, contidos nas leis e atos regulamentadores, tais como assistência integral, universalidade, hierarquização e regionalização de serviços, além do controle social.

Enfoca como prática humanizadora o tratar com as dificuldades de acesso dos usuários aos serviços e suas injustas conseqüências - as filas de espera, a necessidade de ampliação dos mecanismos de comunicação e informação, o incentivo a formas de acolhimento que levem à otimização dos serviços e ao acesso dos usuários a todos os níveis de atenção do siste- 
ma de saúde, com mecanismos de referência e contrareferência.

No caso dos serviços que prestam atenção básica, por exemplo, propõe-se à elaboração de projetos terapêuticos individuais e coletivos para os usuários e sua rede social, formas de acolhimento e inclusão de clientela, práticas que incentivem a diminuição do consumo de medicamentos, fortalecimento das relações entre as equipes de saúde e os usuários, além do estabelecimento de ambiência acolhedora.

Enfatiza, ainda, a necessidade do desenvolvimento da gestão participativa nas instituições públicas de saúde envolvendo trabalhadores e usuários na tomada de decisão dos atos de gestão, mediante a instalação de conselhos gestores em unidades hospitalares.

Essa orientação se conforma à noção, com a qual concordamos, de que a presença dos usuários nas decisões do aparelho de Estado, exercendo o controle social, constitui um dos modos mais eficazes para garantir a implementação de medidas que possam efetivar a humanização dos serviços de saúde, evitando que os agentes do poder público, mesmo que motivados pelo princípio da beneficência - fazer o bem, terminem na prática assumindo condutas paternalistas e autoritárias, contrárias à vontade autônoma das pessoas ou das comunidades.

Cabe também ser lembrado que, no Estado de São Paulo, a humanização dos serviços é uma das diretrizes da política desenvolvida pela Secretaria de Estado da Saúde, visando um padrão de qualidade centrado na humanização do atendimento, com garantia de orientação e informação aos pacientes sobre os serviços prestados, no atendimento de qualidade na unidade de saúde, realizado no menor tempo possível e na existência de ambiente que priorize verdadeiramente a resolução dos problemas dos pacientes. Nos últimos anos foram constituídas comissões de humanização junto aos órgãos centrais e em diversos estabelecimentos de saúde, o que tem propiciado expandir a reflexão sobre as práticas humanizadoras nos serviços (www.saude.sp.gov.br, acessado em 25 de agosto de 2004).

Além disso, outras iniciativas estão sendo realizadas em nome da humanização, tais como a amplia- ção de mecanismos de informação e comunicação, através da criação dos Serviços de Atendimento ao Cliente (SAC), da incrementação de Ouvidorias nas direções Regionais de Saúde, hospitais e ambulatórios de especialidades estaduais, que têm a função de garantir o direito de reclamação, recebendo e investigando queixas de cidadãos, com relação ao mau atendimento em órgãos públicos. Estes instrumentos de humanização podem auxiliar na melhoria da qualidade do serviço prestado e garantir os direitos do cidadão-usuário do serviço público.

Cabe também, a título exemplificativo, destacar iniciativas como a da Secretaria Municipal de Saúde de São Paulo, que vem desenvolvendo nos últimos anos projetos orientados para práticas humanizadoras, principalmente em unidades voltadas para atenção básica da saúde, tais como o Programa de Acolhimento (www6.prefeitura.sp.gov.br/secretarias/saúde/ projetos_prioritários/ooo2, acessado em 25 de agosto de 2004).

\section{Finalizando}

O conhecimento das condições por que passa grande parte dos serviços de saúde nos mostra que é necessário que se reformule as práticas cotidianas de gestão e de atenção à saúde, substituindo culturas institucionais, infelizmente ainda muito disseminadas entre nós, que tendem, infelizmente, a "coisificar" as pessoas que utilizamos serviços de saúde intentando a satisfação de suas necessidades.

Assim, se entendemos e valorizamos o fato de que políticas públicas de humanização da atenção à saúde vêm sendo consolidadas nos últimos anos, devemos considerar que, para melhor atingir seus objetivos, devam se orientar pelo denominado princípio da humanidade, pelo qual o homem deve ser considerado como o centro da ação ética, aceitando-se a aplicação do imperativo categórico kantiano que afirma que a ação eticamente adequada deve considerar o homem como um fim em si mesmo, e não somente como um meio de satisfação dos interesses das diversas forças sociais atuantes na atenção em saúde. 


\section{Referências Bibliográficas}

BRASIL. Ministério da Saúde. HumanizaSUS: política nacional de humanização. Brasília, , 2003.

BRASIL Ministério da Saúde. Programa Nacional de Humanização da Assistência Hospitalar. Brasília, 2001.

FORTES P. A. C. Ética e Saúde. São Paulo, Ed. Pedagógica Universitária, 1998.

RECH C. M. F. Humanização hospitalar: o que pensam os tomadores de decisão a respeito? São Paulo 2003. Dissertação (Mestrado em Saúde Pública) - Faculdade de Saúde Pública, Universidade de São Paulo
RIBEIRO C. R. O. O conceito de pessoa na perspectiva da bioética secular: uma proposta a partir do pensamento de Tristram Engelhardt. São Paulo, 2002. Tese (Doutorado em Saúde Pública) - Faculdade de Saúde Pública, Universidade de São Paulo

ZOBOLI E. L. C. P. Bioética e atenção básica: um estudo de ética descritiva com enfermeiros e médicos do Programa de Saúde da Família. São Paulo, 2003. Tese ( Doutorado em Saúde Pública) - Faculdade de Saúde Pública, Universidade de São Paulo 